\title{
Pedagogical Management of Learning Activities of Students in the Electronic Educational Environment of the University: A Differentiated Approach
}

\author{
Vera Ivanovna Toktarova ${ }^{1}$ \\ ${ }^{1}$ Mari State University, Republic of Mari El, Russia \\ Correspondence: Vera Ivanovna Toktarova, Mari State University, 424000 Republic of Mari El, Russia.
}

Received: November 16, 2014 Accepted: January 5, 2015 Online Published: April 28, 2015

doi:10.5539/ies.v8n5p205 URL: http://dx.doi.org/10.5539/ies.v8n5p205

\begin{abstract}
The present study considers issues related to the planning and implementation of the system of pedagogical management of learning activities of students in the context of modern electronic educational environment of the higher education institution. As a methodological basis considered a differentiated approach based on flexible individual learning paths. The study provides the results of the pilot testing of students studying on the faculty "Applied Mathematics and Informatics" carried out to evaluate and determine the degree of influence of pedagogical management in the electronic educational environment on improvement of the quality of professional training of students in the university.
\end{abstract}

Keywords: informatization of education, e-learning, pedagogical management, electronic educational environment, a differentiated approach, educational process, learning activities, high school

\section{Introduction}

Significant changes in the information support of society objectively require a review of approaches in the system of higher education (Al-Qahtani \& Higgins, 2013).

The development of e-learning in our country is one of the strategic objectives of the educational system. Under the provisions of the Federal Law "On Education in the Russian Federation", the institutions implementing educational activities, have the right to use e-learning in the implementation of educational programs (The Federal Law, 2012). Thus there should be provided all the conditions for the functioning of the electronic educational environment (EEE) that ensures the acquisition by the students of educational programs to the full extent, regardless of their location. The Order of the Ministry of Education and Science of the Russian Federation (The Order, 2014) signed this year, has determined the procedure for the application by the institutions of e-learning and distance learning technologies in the implementation of educational programs. Nowadays taking into account the specifics of time, the electronic educational environment of the higher education institution shall allow fully implementing the conceptual approaches of the federal state educational standards of higher professional education (FSES HPE) and being an effective means for implementing e-learning. Consequent systemic changes affect all components of the educational process and functional links between them, transform goals and objectives, forms, methods and means of teaching.

By virtue whereof the current issue shall be the study of the problem of planning and implementing a system of pedagogical management of learning activities of students in the electronic educational environment based on the co-management of the educational process aimed at the acquisition by the students of the necessary competencies, ensuring fulfillment of the social order of society in the preparation of specialists with higher professional education.

\section{Methods}

In the preparation of the material for the study a complex of methods has been used:

- Theoretical research: the study and synthesis of national and international experience on pedagogic management of the educational process in the computer-based environment, the analysis of literature data and sources on pedagogical, psychological and technical issues relating to the computerization of the educational process and e-learning; analysis of existing and future regulations, the federal state educational 
standards, curricula, programs, etc.;

- Empirical research: observation of the educational process, learning activities of the students; conducting educational evaluation, comparison and collation, statistical processing of the research results, experimental teaching.

\section{Results}

Pedagogical management as an independent subject has been actively studied since the end of the twentieth century, although some problems constituting its essence, have been discussed earlier in the works on pedagogy and psychology of education (Reeves, 2005). The analysis of the works revealed a complex of the issues under consideration: theoretical-historical and methodological aspects of the management in social systems (Afanasyev et al.); management of the educational institution (Davydenko et al.); management of learning and cognitive activities of students (Bespalko et al.); psychological characteristics of the management process (Leontiev et al.), active using of different learning style models (Dunn et al.), the management of the educational process (Arkhangelsky et al.).

Pedagogical management is a special kind of activities of all subjects of the educational process aimed at achieving goals and using the forms and methods for facilitating its functioning and development as a pedagogical system (Ignatieva, 2012).

According to research (Talyzina, 1984), pedagogical management is inextricably linked with certain effects, necessary for the implementation of target criteria of the educational process: maintenance within established boundaries (functioning) or transition to a new state (development). According to the authors (Shamova et al., 2007), this type of management is aimed at regulating the educational process in order to transfer it to a higher level. Babansky (1982) defines the essence of the management in its optimization, which provides the following conditions for its solution:

- Integrated task scheduling;

- $\quad$ Specification of the components of the educational process on the selected model;

- Comparative evaluation of different paths of the educational process with a view to their situational adequacy;

- $\quad$ Time efficient of methods, forms, techniques of teaching and organization of the process;

- Commitment to the cost-effective and appropriate expenditure of time, conditions and resources.

The description of pedagogical management based on didactic orientation has been mentioned in the works of Amonashvili (1990) who defined learning as a process forming and managing learning and cognitive activities of the students. This author pays a particular attention in pedagogical management to the development of students' motivational attitude to learning activities.

The learning process with the use of the computer can be represented as a management system where the student acts as a subject of learning, while the computer represents an educational medium (Krasilnikova, 2009). In this system the student enters a new category due to the fact that in its form the educational and cognitive activity in the e-learning environment is an individual process, but it should be mentioned that this process is carried out under a certain algorithm. The scientists have carried out the analysis of learning systems and pointed out four types of the implementation regime of pedagogical management in the study (Mashbits et al., 1989):

- $\quad$ Direct management: the system provides the learning task, the student can ask questions only from the certain task area, assistance in solving the tasks is determined by the learning system;

- Indirect management: the system provides the student with some problem that needs to be formalized in the form of a learning task, such as planning of professional situations or modeling of social situations;

- Dynamic management: the learning task provided is solved simultaneously by students and the learning system. This type of management makes high demands on the formation of the "human-computer" dialogue, management algorithm and the provision of assistance;

- The computer as a means of management of learning activities: the teacher plays a leading role in this system, as he/she needs to formulate the learning tasks and develop the necessary assistance to the students.

According to the presented types of management in educational systems, the organization of learning activities in the higher education institution is very complex and requires the solution of not only the technical and technological problems, the special significance is given to psychological and pedagogical principles of constructing the "student-computer" dialogue, playing an important role in the implementation of training 
effects.

Methodology of the cybernetic approach defines the management as a process of converting the information in accordance with a certain purpose. The environment is necessary for the implementation of the management as it represents a set of conditions in which the interaction occurs. In the context of the modern educational process in higher education institution in the implementation of e-learning this is an electronic educational environment. The organization of educational and teaching activities in the electronic educational environment results in a change of methods and means of education, knowledge sources, transforming the role and functions of the teacher, as well as the ways of the teacher's communication with students (Bondarouk \& Ruël, 2011). The teacher takes new tasks: the formation of the current knowledge, active work in the e-learning environment, continuous professional training in the field of information and communication technologies, and other tasks.

In various sources the electronic educational environment is understood as follows:

- The system of instrumental means and resources ensuring the conditions for the realization of educational activities based on information and communication technologies (GOST, 2011);

- Pedagogical structure, which aims at creating conditions for the organization and development of innovative processes of interaction of objects and active subjects of this environment (Lebedeva, 2010);

- Multiple-aspect, holistic, socio-psychological reality, which provides a set of necessary psychological and pedagogical conditions of modern learning technologies and program-methodological training techniques that are based on modern information technologies providing necessary maintenance of the cognitive activity and an access to information resources (Krasilnikova, 2009).

All these definitions in one way or another include program-technical and psychological-pedagogical conditions and means ensuring the effective support of the educational process. According to research (Zakharova, 2003), there are four basic principles the electronic educational environment is characterized by:

- Openness, providing the students with a free access to educational material;

- Structured and resource redundancy, causing developmental impact of the environment on the student on the basis of individual learning paths and the variety of educational material;

- Integrity, associated with informative and activity component of the electronic educational environment, which provides the opportunity to select the optimal training material and choose the types of activities;

- Non-linearity, suggesting the presence of three levels of environmental structure; the first type is called invariant (general), the second type is a specialized one that includes professional orientation, while the third individual type is created in the course of learning activities of students.

Modern electronic educational environment of the higher education institution shall provide each student with a set of teaching materials, an access to virtual libraries, communication with teachers and other students, as well as the possibility of arranging webinars, realization of personal calendars, news boards, and record books. In addition, for the effective implementation of the electronic educational environment it is necessary to support the system of adaptation depending on the individual abilities of students, the entry-level qualification and other factors. The development of such an algorithm is a labor-intensive and high-tech process, but it has some obvious advantages.

Professional training in terms of the electronic educational environment can be represented as a didactic system with a certain set of interacting components and control functions. In this case a teacher or a computer training system acts as a managing agent, while the student is agent-managed. The interaction between them is based on the technical means by transmitting, perception and converting information streams in the question-and-answer mode (Krasilnikova, 2009). Management efficiency will be achieved provided a clearly defined goal, algorithmization of actions, methods and criteria for the formation of channels of direct communication and feedback. According to research (Bespalko, 1989), the management algorithm is a system of tracking and correcting educational-cognitive activities of the student, aimed at maintenance of the sufficient stability in the acquisition of educational material and the achievement of learning objectives. Successful learning activities of the student depend on the well-grounded algorithm; in this case the presence of a feedback channel is the foundation of high-quality management of the professional training process. Bespalko (1989) in his studies stresses the importance of feedback in the systems involving continuous analysis and diagnosis of the main factors, which include the level of materials acquisition $(\alpha)$, scientific character of the subject study $(\beta)$, awareness of materials acquisition $(\gamma)$ and the degree of its automatization $\left(\mathrm{K}_{\tau}\right)$.

Considering the learning activities in terms of e-learning, the algorithmization of the student's actions 
(Ospennikova, 2007) and the transfer of teacher's functions to some kind of computer-based learning tool play an important role in the planning of the EEE. In the construction of the algorithm of the management of learning activities in the electronic educational environment it is appropriate to take into account the specific phase of the learning process, proposed by Bespalko and Talyzina (Figure 1).

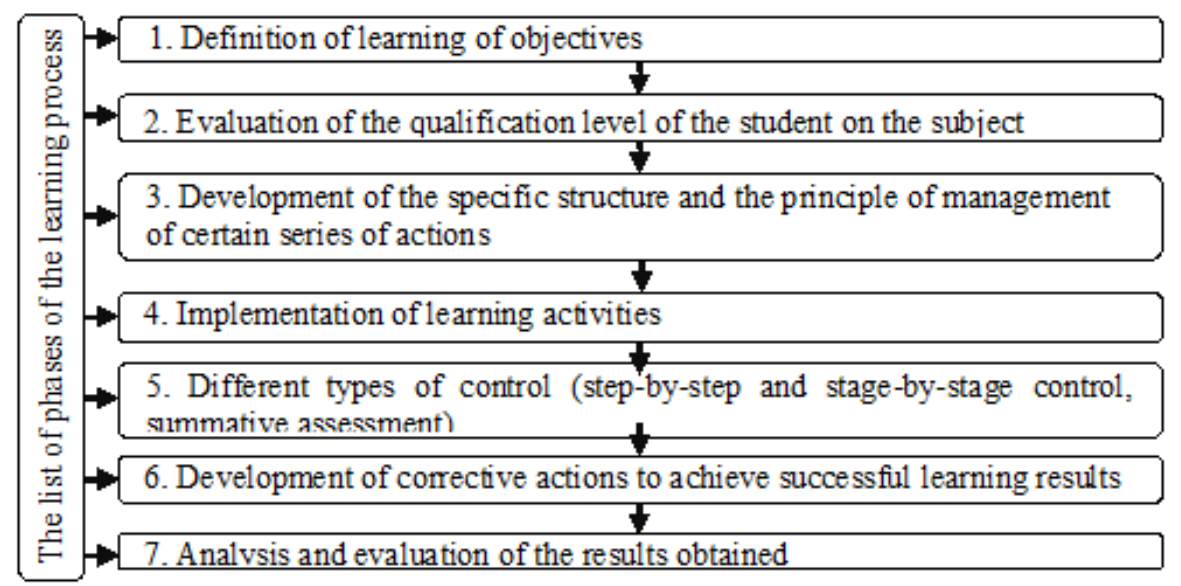

Figure 1. Phases of the learning process

The analysis of the pedagogic management in the modern electronic educational environment from the perspective of the provisions of the classical management school has led to the conclusion that it includes all the functional stages:

- Planning: construction of the general model of the course of study, the description of the objectives, strategies for achieving results, a set of competencies of students, methodological techniques, criteria and indicators for assessment and diagnosis; scheduling of the learning process; the description of the individual learning paths and routes in acquisition of the educational content; analysis of the initial level of qualification, individual characteristics and personal qualities of the student;

- Structuring of the educational process: the conduct of the learning process of students through individual learning paths and flexible adaptation algorithm; involvement of students in the implementation of their own educational activities;

- Motivation: stimulation of the interest through arrangement of comfortable conditions in accordance with the psychological and personal characteristics of students; students acceptance of the ideas of freedom and responsibility, ensuring the involvement in the procedure of choice, personal identity, self-analysis;

- Control: the use of various methods for assessment and diagnosis; involvement of students in the process of self-evaluation and self-control;

- Coordination: the use of technological methods and flexible adaptation algorithm, providing systematic coordination of components of the educational system aimed at improving the learning activities and management process.

Furthermore, considering the aspects of pedagogic management in the electronic educational environment (Ignatieva, 2012) from the perspective of didactics, we can conclude on the need for using specific didactic principles both in the construction of the educational process and the design of the electronic environment where the pedagogic management shall be executed:

- Modularity: the formation of the full content of educational material through a plurality of finished modules of different orientation, complexity, completeness, etc.;

- Problematicity: the organization of learning activities in relation to a specific problem, the solution of which involves passing known stages actualizing different skills of working with the material and supporting the learning motivation;

- Subjectivity: accounting for individual characteristics and personal qualities of the subjects of the 
educational process, creating the possibility of self-selection of the content, objectives and learning paths;

- Interactivity: the organization of joint activities, co-creation in developing objectives, means and methods of the educational process, the optimal construction of the "human-computer" dialogue;

- Intellectualization: the development of skills to work with knowledge in a wide range of opportunities, the generation of innovations and commercialization of the knowledge;

- Reflexivity: the evaluation of new knowledge based on the previous experience, the ratio of the information and personal knowledge, self-analysis and evaluation of the successful achievement of objectives related to the learning activities;

- Valeological principle: the development of skills to work with the knowledge based on understanding and application of psychological mechanisms, their correct use, preservation of mental and physical health of the participants of the educational process.

Classical learning style models can be effectively applied in the implementation of learning activities in the electronic educational environment. These models allow enhancing the quality of the educational process. Learning styles are based on the individual psychological characteristics of the cognitive structure of personality, the student's inclination to use certain modes of interaction with the learning information. Knowing the characteristics of the student's learning style, we can choose individual technologies of his/her teaching and self-education that allow to promote to the fullest extent his/her mental and personal development in general.

Proponents of learning style models postulate that students learn in different ways. According Neil D. Fleming's VARK model (Fleming, 2001), which expanded of the earlier neuro-linguistic programming model, people are classified by the channels of information perception: visual, aural, read-write and kinesthetic learners. Fleming claimed that visual learners think in pictures and prefer graphs, charts, maps, diagrams, and different spatial arrangements. Aural learners best learn through listening, discussing topics, using a tape recorder. Read/Write learners like essays, reports, lists, textbooks, definitions, and taking notes. Kinesthetic learners prefer to learn via experience, laboratories, science projects, recipes and solutions to problems. VARK model offers suggestions for approaches for matching teaching or learning styles.

Dunn and Dunn Learning Style Model, which measured by the Productivity Environmental Preference Survey (Dunn, 1990), defines learning style as "the way in which individuals begin to concentrate on, process, internalize, and retain new and difficult information" (p. 353). The model suggests five learning style stimuli and several elements within each of them. They are environmental (sound, light, temperature, and room design), emotional (motivation, persistence, responsibility, and structure), sociological (learning alone, in a pair, with peers, with a teacher, and mixed), physiological (perceptual, intake while learning, chronological energy pattern, and mobility needs), and psychological Processing (global or analytic, hemisphericity, and impulsive or reflective).

Other model is associated with a binary division of learning styles, developed by Felder and Silverman (Felder, \& Silverman, 1988). It asserts that individuals have preferences between four pairs of extremes: Active-Reflective, Sensing-Intuitive, Verbal-Visual and Sequential-Global. The ILS (Index of Learning Styles) provides scores for showing the strength of an individual's preferences.

In the organization of the pedagogical management, based on the differentiated approach, it is recommended to use a set of models of learning styles that complement each other and provide for consideration of the different aspects of learning. In accordance with the above-mentioned principles and learning styles, the educational process is considered as a non-linear interaction of its participants, multiple routes of its development (Rogers, 1994). Therefore, pedagogical management of the learning activities of students in the electronic educational environment involves changing the model of the educational process-from the linear model (application of the inflexible general scheme) to the non-linear model (the use of flexible individual paths based on a differentiated approach). Thus the essence of differentiation, including the adaptation of the educational process to the personal characteristics of the students, promotes the implementation of the following objectives: creation of favorable conditions enabling each student to implement their opportunities in accordance with their individual abilities and psycho-physiological qualities; personal intellectual potential fulfillment.

In the context of the electronic educational environment of the Department of Applied Mathematics and Informatics of the Federal State Budgetary Educational Institution of Higher Professional Education (FSBEI HPO) "Mari State University" there has been developed and implemented a model of pedagogical management of learning activities of students on the basis of the differentiated approach (Toktarova, 2013), that allows the following: 
- Nonlinearity of the educational process that promotes personalization of learning activities and providing different levels of education;

- Accounting for individual characteristics of students: type of mental activity, levels of acquisition of new knowledge and development of memory, entry-level qualification, professional training rate; adaptation of the environment to the learner according to these indicators;

- The implementation of flexible algorithm of pedagogic management of the educational process: providing the students with opportunity to independently choose a learning path, its subsequent adjustment on the basis of the analysis of results of student's learning stages.

For construction of a personal profile of the student and the subsequent implementation of the differentiated approach prior to the beginning of the educational process the student is invited to register and pass the tests to determine his/her individual characteristics and qualities, as well as when it is necessary to check the initial knowledge on the subject. As parameters for the differentiation selected the following parameters:

- Personal-psychological mindset of the student representing an individual way of processing and conversion of incoming information, determined by the method of Bruner J. (Bruner, 1977). There identified four basic types of mindset: objective, figurative, sign-oriented, symbolic types of mindset;

- The level of mastering of the educational material $K_{\alpha}$, proposed by Bespalko (1989). The differentiation under the level of acquisition of the educational material means to range the student in one of the following groups depending on the indicator value $K_{\alpha}$ : a group, the members of which are ready for the further education and self-improvement $\left(K_{\alpha} \geq 0.7\right)$, or a group where the students shall re-examine the completed module in order to improve their results $\left(K_{\alpha}<0.7\right)$;

- Entry-level qualification of the students on the subject.

Depending on the indicators of the personal profile the student is provided with the educational material composed in accordance with the following criteria:

- Presentation type of the educational material: textual description; video lessons (video lectures, video practicum, webinars); audio lectures (audio dictionaries, audio manual);

- Difficulty level: elementary, intermediate, advanced levels;

- Volume: brief introduction, detailed study;

- Form of organization of the learning activities: theoretical studies, laboratory practice, control of knowledge and skills, a comprehensive study of the course.

The implementation by students of control measures during the educational process allows to adjust their further individual paths of learning activities. By creating a system of pedagogic management the students will have the opportunity to learn disciplines in a format convenient for them, choosing the content and volume of the educational material, the manner of its presentation, the form of knowledge control, and receiving recommendations and comments of the electroniceducational environment in the educational process that promotes the optimal construction of the "human-computer" dialogue.

\section{Discussion}

During 2013-2014 academic years with the participation of students of $2^{\text {nd }}-4^{\text {th }}$ university courses studying on the faculty No. 010400-“Applied Mathematics and Informatics" there conducted an experimental training on the disciplines of professional cycle in the developed electronic educational environment. In order to determine the psychological readiness and conduct the analysis of the motivational component of the students under study there conducted interviewing and questionnaire survey, which were attended by 87 students. The results showed that the absolute majority of respondents $(96.55 \%)$ considered e-learning as a relevant form of education, $94.25 \%$ of respondents pointed out the need to develop and arrange the educational process in the framework of the modern electronic educational environment. According to students, an important advantage of the electronic educational environment is the opportunity to study in conditions of a constant free access, regardless of time and location. $89.66 \%$ of the respondents positively responded to the question "Does the existence of different learning paths in the electronic environment impact on the quality of education?" According to $97.70 \%$ of the students, the implementation of flexible algorithm of pedagogic management in the electronic educational environment based on the individual characteristics of the student is a prerequisite for improving the effectiveness of their learning activities.

In order to check the effectiveness of the model of pedagogical management in the electronic educational 
environment the pedagogical experiment has been conducted, the purpose of this experiment was the evaluation and determination of the impact of the model implementation on improving the quality of students training. The experimental group (EG) consisted of 44 students, while the control group (CG) consisted of 43 students. Uniformity and stability of the groups were provided by the fact that the choice was made on the basis of the intellectual abilities of students, determined on the results of earlier studies using the control test on residual knowledge and GPA. The students of the experimental group were educated within the electronic educational environment, while the students of the control group were educated in a traditional way. For research the following hypothesis has been developed: the students in the experimental group, held a series of lectures within the developed electronic educational environment, should have the level and quality of acquisition of the educational material higher than those of students in the control group. The experiment was conducted in the framework of study time during one semester.

The level of acquisition of knowledge and the ability was evaluated under the results of the test and independent works. The results showed that this indicator of the students in the experimental group was higher up by $17.08 \%$ in average, compared to the students in the control group. In order to evaluate the effectiveness of knowledge on the course unit used the summarized index, which is calculated by the formula $D=\frac{M}{n \cdot p} D=\frac{M}{n \cdot p}$, where $M$ means the total number of correctly completed tasks, $p$ means the number of scheduled tasks, $n \cdot n$ means the number of students. The average value of the indicator $D$ on the basis of the four control tests is $87.52 \%$ in the experimental group and $72.06 \%$ in the control group.

For calculation of the relative efficiency of the volume of the acquired educational material used the indicator $Q_{v}=\frac{U_{k p}-U_{t m}}{U_{t m}} \cdot 100$, where $U_{\mathrm{kp}}$ means the scope of knowledge acquired in the learning process in the electronic educational environment, $U_{\mathrm{tm}}$ means the scope of knowledge acquired by means of traditional methods. The average value of the efficiency indicator of the scope of the acquired material amounted to $14.72 \%$.

After completion of the course, participants in the experimental group were asked to pass a questionnaire survey, under the results of which $100 \%$ of the students noted the positive aspects and the need to implement a system of pedagogical management of learning activities in the electronic environment; $95.45 \%$ of the respondents believe that the lessons conducted within the electronic educational environment resulted in gaining more interest in the subjects; $88.64 \%$ believe that such method allows to organize their knowledge; $93.18 \%$ - to impart skills of independent work; $97.72 \%$ of the students indicated an increased level of knowledge acquisition through free access to the educational materials, regardless of time and location.

The results obtained ascertain the full experimental confirmation of the hypothesis of the present study.

\section{Conclusion}

The specificity of pedagogical management in the electronic educational environment of the higher education institution lies in the necessity of its development at a higher level, professional orientation and detailed didactic presentation. The implementation of the environment under study ensures the adaptability of the learning process to the individual characteristics and abilities of students, the integrity and effectiveness of their acquisition of basic educational programs, and, as a consequence, the improvement of the quality and efficiency of the educational process of the higher education institution.

Prospective lines of development of the ideas containing in the present study are the following: the analysis and development of various methodologies of pedagogic management, aimed at the implementation of the systemic changes in the educational process of the higher education institution in the context of e-learning and mobile learning.

\section{Acknowledgements}

The present study has been conducted with financial support from the President of the Russian Federation for young Russian PhD scientists under the grant project MK-1634.2014.6.

\section{References}

Al-Qahtani, A. A., \& Higgins, S. (2013). Effects of traditional, blended and e-learning on students' achievement in higher education. Journal of Computer Assisted Learning, 29(3), 220-234. http://dx.doi.org/10.1111/j.1365-2729.2012.00490.x

Amonashvili, Sh. (1990). Personality-human basis of the pedagogical process. Minsk: University Publishers. 
Babansky, Y. (1982). Optimization of the education/bringing-up process: methodological foundations. Moscow: Prosveshcheniye Publishers.

Bespalko, V. (1989). Components of the pedagogical technology. Moscow: Pedagogy.

Bondarouk, T., \& Ruël, H. (2011). Dynamics of e-learning: theoretical and practical perspectives. Introduction to special issue. International Journal of Training and Development, 14(3), 149-154.

Bruner, J. (1977). Cognitive psychology. Beyond the immediate information. Moscow: Progress.

Dunn, R. (1990). Understanding the Dunn and Dunn learning style model and the need for individual diagnosis and prescription. Reading, Writing, and Learning Disabilities, 6, 223-247.

Felder, R. M., \& Silverman, L. K. (1988). Learning styles and teaching styles in engineering education. Engineering Education, 78(7), 674-681.

Fleming, N. D. (2001). Teaching and learning styles: VARK strategies. Christchurch, New Zealand: N.D. Fleming.

Ignatieva, E. (2012). Pedagogical management of learning activities of students in the modern higher education institution: A monograph. Saint-Petersburg: "LEMA" Publishers.

Krasilnikova, V. (2009). Theory and technologies of the computer-based training and testing: A monograph. Moscow: The House of Pedagogy, IPK GOU OGU.

Lebedeva, M. (2010). Distance learning technologies: design and implementation of educational courses. Saint-Petersburg: BHV-Petersburg.

Mashbits, E., Andrievskaya, V., \& Komisarova, E. (1989). The dialogue in the learning system. Kiev: High School.

Ospennikova, E. (2007). Modern concepts and learning models as the basis of pedagogical planning (design): A tutorial. Perm.

Reeves, T. (2005). No significant differences revisited: a historical perspective on the research informing contemporary online learning. In G. Kearsley (Ed.), Online learning: Personal reflections on the transformation of education. Englewood Cliffs, NJ: Educational Technology Publications.

Rogers, C. (1994). A view of psychotherapy. On becoming a person: [trans. from English.]/general editorship and pre-editing by Isenina E.I. Moscow: Progress-Everest.

Shamova, T., Davydenko, T., \& Shibanova, G. (2007). Management of educational systems: A tutorial. Moscow.

Talyzina, N. (1984). The management of a process of knowledge acquisition. Moscow: MSU.

Toktarova, V. (2013). Training and methodological support of the implementation of the main educational programs in the electronic educational environment of the higher education institution. Proceedings of the Volgograd State Pedagogic University, Series "Pedagogical Sciences”, 2(77), 28-32.

Zakharova, I. (2003). The formation of the information and educational environment of the higher education institution. The abstract of the EdD thesis. Tyumen.

\section{Copyrights}

Copyright for this article is retained by the author(s), with first publication rights granted to the journal.

This is an open-access article distributed under the terms and conditions of the Creative Commons Attribution license (http://creativecommons.org/licenses/by/3.0/). 